\title{
Study of Equipment Presses of Cocoa Powder (Theobroma cacao,L) to Produce Quality Fat Cocoa and Analysis of the Resulting
}

\author{
Omil Charmyn Chatib ${ }^{\#}$, Sandra ${ }^{*}$, Harly Meta Asbani ${ }^{1}$ \\ \# Agriculture Engineering, Andalas University, Padang, Indonesia \\ E-mail:omil_c@yahoo.co.id \\ * Agriculture Engineering, Brawijaya University, Malang, Indonesia \\ ${ }^{1}$ Laboratory of Food Processing and Agricultural Products, Andalas University, Padang, Indonesia
}

\begin{abstract}
This study was conducted to determine the performance of the press tool brands CARVER type Model 3912 Hydraulic Unit in producing cocoa fat and then analyzing the product. This research was conducted at the Laboratory of Food and Agricultural Products Processing and Chemistry Laboratory, Agricultural Products Biochemistry Faculty of Agricultural Technology, University of Andalas, Padang in April-June 2014. In this study, conducted observations such as pressure, temperature, and time presses ideal in the process. While the manufacturing unit made a tool to improve the performance of the instrument and the acquisition of fat that is carried out according to treatment pressure of $8.05 \mathrm{MPa}$ at a temperature of $130{ }^{\circ} \mathrm{C}, 150{ }^{\circ} \mathrm{C}$ and $170{ }^{\circ} \mathrm{C}$ for each repetition. After that, analyzing the free fatty acids, iodine number, saponification number, and the moisture content of the product is done. Based on studies conducted by the information obtained from the data base in the presses, pressure $8.05 \mathrm{MPa}$ and a temperature of $130{ }^{\circ} \mathrm{C}$ obtained average - average yield of $51.57 \%$ fat for 3 repetitions. This explains that the tool operates properly. As for test analysis, free fatty acids, iodine number, saponification number, and moisture content for each sample at all treatment is not obtained in accordance with the quality standards of Fat Cocoa determined by ISO 3748:2009.
\end{abstract}

Keywords - Cocoa; press Tool Brands; Fat Cocoa

\section{INTRODUCTION}

Processed cocoa main current is fat, and cocoa powder. Fat cocoa became widely used raw material for processed food products, cosmetics, and other products. So the demand is so fat cocoa high in demand and prices than other cocoa processed. Thus the need to do the process of separation in order to obtain the corresponding characteristics of the cocoa fat. The process of separation of cocoa butter can be done through several ways, ie by using solvent extraction or by pressing were performed using tools such as pressing machine.

Use the solvent extraction method has the disadvantage that participate dissolved partially unwanted components from cocoa fat, like phospolipida. In addition, the separation process is required between the back fat and solvents, and can reduce the typical aroma of chocolate that gives negative effect on the quality of cocoa butter to be generated. So this shows that the use of the method of extraction is less favorable cost required is even greater. The use of the pressing technique is considered far more practical and cheap, especially to the scope of use by small and medium industries. Therefore, how pressing is still considered to be an option in the extraction of cocoa fat. Seeing more than half cocoa beans meat (nib) is so fat needs to be maximized.

But this pressing tool is still considered optimal in creating the optimal fat cocoa. Because it has not gotten the ideal treatment tool presses ranging from equipment components, temperature up to the pressure applied. So it needs to be innovation on the pressing tool. Innovation is given to the components to make it more presses can reduce the level of fat loss. This shows the pressing tool can be further optimized with the appropriate treatment, the hope of achieving good cocoa fat will be achieved. So is the pressure and temperature greatly affect the resulting fat gain. Because the effects of pressure and temperature simultaneously will cause the melting point of cocoa butter fat down and was produced during the pressing process lasts until the cocoa powder completely - completely dry.

Cocoa butter is a natural fat obtained from cocoa nib separation process results by the method of pressing. For presses, hydraulic press equipment operated at a pressure of 1.976 $\mathrm{MPa}, 2.964 \mathrm{MPa}$ and $3.951 \mathrm{MPa}$ and the temperature is $100{ }^{\circ} \mathrm{C}, 125^{\circ} \mathrm{C}, 150{ }^{\circ} \mathrm{C}$ for 5 minutes was given to each - 
each temperature were applied. The results showed that the yield stress is affected cocoa fat. So, the higher the applied pressure and the higher the temperature, the more fat cocoa can be produced from pressing [1].

Assessment or cocoa butter press machine research is needed to increase capacity of the results. Equipment or cocoa butter press machine has a main component of the hydraulic, cylinder block (press space) consisting of a plunger, filter and retainer, and a support structure. With studies on surface area squeezer and process parameters, namely temperature, pressure, and time, are expected to be designed and a prototype design press machine fat better performance. Based on the description above, it is necessary to study with the title: "Study of Equipment Presses of Cocoa Powder (Theobroma cacao,L) to Produce Quality Fat Cocoa and Analysis of the Resulting ".

The objectives of this study is to evaluate and test-fat cocoa press tools to better performance to get maximum fat cocoa with parameters of pressure, temperature and the optimum time in the pressing.

The benefit of this research is to obtain data on the cocoa butter pressing technology to pressure, temperature, and the optimum time to produce cocoa butter and analyzes obtained.

\section{MATERIALS AND METHODS}

\section{A. Materials and Tools}

The materials used in this study is the cocoa beans that have been fermented TSH 858 varieties obtained from cocoa farmers in West Sumatra, solid iron, iron pipe, pan, and filter cloth. Meanwhile, the tool used is a manual roasters, Carver Hydraulic Unit Model 3912 instrument equipped presses cocoa beans pressure and temperature controller, blender, digital scales, calculators, ovens, knives along with other supporting equipment.

\section{B. Methodology}

This study was conducted in an effort to add more units to the press tool cocoa fat but units of hydraulic or expeller pressing tool is first modified to obtain optimal results from the previous fat. Suppressor units initially square shaped then reformed into a round with the hope that the pressure exerted greater. The amount of cocoa butter that can be extracted depends on the success or failure of modifications made to the appliance unit, and also refers to the pressing duration, temperature, and time is given when pressing process take place.

1) Press: Press media tools fats have the first two components of the outer ring as an adhesive and a second component that is solid iron that serves as a suppressor. Samples were then pressed using a hydraulic press which has been equipped with pressure and temperature with a brand CARVER Type Hydraulic Unit Model 3912 with a maximum force of 24,000 pounds on the tool. Style contained in this press equipment including 10,000 pounds, 15,000 pounds and 20,000 pounds, equivalent to 1, $976 \mathrm{MPa}$, $2.964 \mathrm{MPa}$ and $3.951 \mathrm{MPa}$. However, in this study used a consistent pressure of 24,000 pounds or the equivalent of 8.05 $\mathrm{MPa}$ to hold for 10 minutes on each - each treatment until the fat out and flowed into the container shelter. Heating given by adjusting the temperature found in the tool temperature 1300C, $1500 \mathrm{C}$ and 1700C. Fat flowing fit and weighed and analyzed.

2) Cocoa Fat : Cocoa fat removed from the cocoa nib felted manner. Cocoa nib which has warm conditions incorporated into the tool clamp. At the cylinder wall tool given the holes that act as filters for compressed result. Results of fatty liquid that comes out will pass through the holes and the nib seed oilcake will remain stuck in the cylinder tool. The yield of fat obtained from the compression process is influenced by several factors, including, cocoa nib temperature, moisture content, particle size nib, nib protein content, felts pressure, and time compression.

\section{Observations}

1) Percentage Weight Leather Cocoa Beans: Measurement of skin levels were calculated using digital scales Cocoa beans weighed $100 \mathrm{~g}$ and peeled to produce a nib. $\mathrm{Nib}$ is then weighed again using digital scales The calculation of the percentage of cocoa seed coat weight can be calculated as follows :

$$
M=\frac{a-b}{a} \times 100 \%
$$

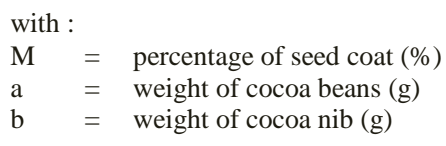

2) Moisture Content of Cocoa Powder Rough Measurement of moisture content using the oven. Materials were weighed using digital scales weighing about 10 grams in a cup aluminum cup dry weight was measured. Furthermore, the material was dried in an oven at $105^{\circ} \mathrm{C}$ until the weight is constant. The water content of crude cocoa powder can be calculated systematically:

$$
M=\frac{b-a}{b-a} \times 100 \%
$$

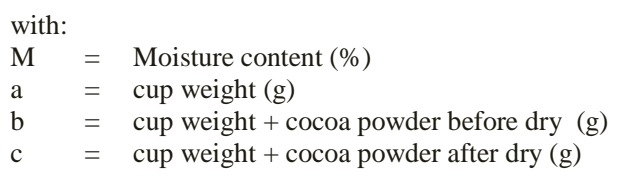

3) The Yield of Fats Cocoa: The yield of cocoa fat is determined by calculating the fat deposited on the sample container, the initial weight of cocoa powder, namely :

$$
R L=\frac{B}{A} \times 100 \%
$$

with:

$\mathrm{RL}=$ The yield of cocoa fat $(\%)$

$\mathrm{A}=$ Sample weight before pressing cocoa powder $(\mathrm{g})$

$\mathrm{B}=$ Sample weight after pressing cocoa powder $(\mathrm{g})$

4) The Weight of Cocoa Bungkil: Cocoa bungkil obtained after the presses. Bungkil is a product obtained from cocoa powder after eliminated most of the fat. Bungkil obtained after presses then weighed using digital scales. Then determined the percentage of initial weight in with a rough powder cocoa.That will be visible differences between the initial weight of the cocoa powder before presses with 
the number of fat cocoa is produced after this that occurred showed presses the difference between input and output.

5) The Moisture Content of Cocoa Bungkil : The measuring water content of bungkil cocoa using the oven. First,the material is weighed using scales, digital weighing around $10 \mathrm{~g}$ of aluminum in a cup which has a cup of dry weight were measured. Further material was dried in an oven at a temperature of $105{ }^{\circ} \mathrm{c}$ until constant weight, then weighed again by using digital scales. Measurement of moisture content is done three times per treatment. To get the final moisture content of cocoa powder. Moisture content rough powder cocoa can be calculated with the equation (2) in systematic.

6) The analysis of cocoa fat samples : The analysis of cocoafat is determined by referring to the Standard cocoa fat SNI i.e., free fatty acids, iod number, saponification number, and the refractive index of the cocoa fat. How to determine the procedure done according to SNI.

\section{a. The Free Fatty Acids (FFA)}

The measurement of free fatty acids is done by way of referring to the procedure of SNI No. 3748 in 2009. Weigh 7 grams fat ingredients cocoa using digital scales are inserted into a $250 \mathrm{ml}$ Erlenmeyer flask, add $75 \mathrm{ml}$ of hot ethanol $95 \%$ and has been neutralized, then add $2 \mathrm{ml}$ of indicator pp and titrated with a solution of $\mathrm{NaOH} 0,1$ until pink color anyway. Determination of free fatty acid levels is calculated by:

$$
F F A=\frac{V x T \times 28,2}{m}
$$

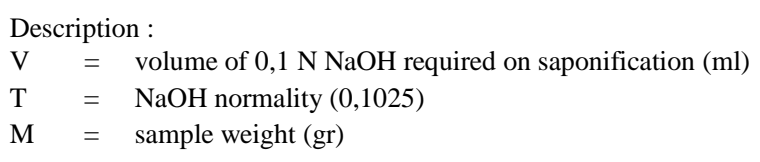

\section{b. The number of Saponification}

The number of saponification obtained by weighing the weight of 5 grams and is inserted into the tube $250 \mathrm{ml}$ Erlenmeyer flask, add $50 \mathrm{ml}$ of alcohol solution of potassium hydroxide and a few grains of the boiling rock, connect an Erlenmeyer flask with a reflux upright above water bath and boil until saponification is finished. Then rinse the appliance with refrigeration and a little distilled water, chill the solution and add $1 \mathrm{ml}$ of the solution into the later becomes pink when titrated with $0.5 \mathrm{~N} \mathrm{HCL}$ to color indicator turns colorless, do assignment duplo, working on assignment count the numbers of saponification by,

$$
\text { Saponification Number }=\frac{56,1 \times N a(N 0-V 1)}{\mathrm{n}}
$$

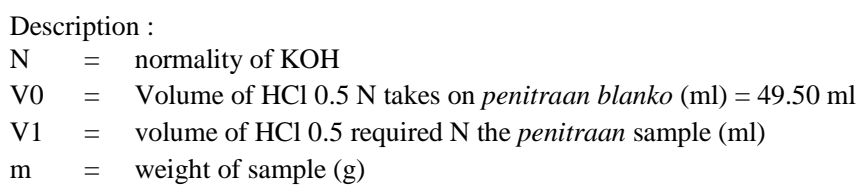

c. The Iod Number

The Iod number obtained by weighing 0.5 grams of material that has been dried and put into an Erlenmeyer flask
$500 \mathrm{ml}$. Add $15 \mathrm{ml}$ cyclohexane solution of glacial acetic acid and add $25 \mathrm{ml}$ of aqueous solution using a pipette wijs hyacinth is then stirred until homogenized. Save for 1 hour in a dark room. Add $20 \mathrm{ml}$ of a solution of $15 \% \mathrm{Kl}$, stirring add $150 \mathrm{ml}$ of distilled water. Subsequent titration with sodium thiosulfate solution $0,1 \mathrm{~N}$ to yellow color is almost lost, then added starch indicator 1-2 ml continued until the blue color disappears, do assignment Duplo and blanko. Then count the ways:

$$
\operatorname{Iod} \text { Number }=\frac{12,69 \times N\left(\mathrm{No}-\mathrm{V}_{1}\right)}{\mathrm{m}}
$$

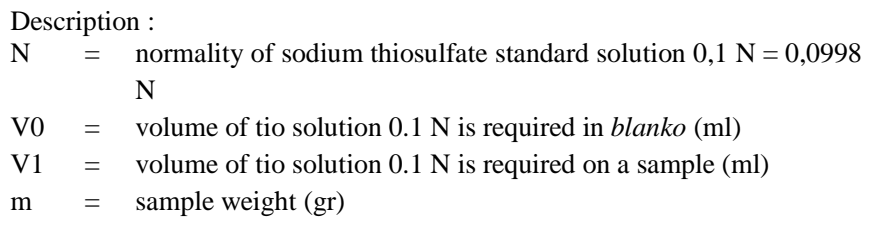

d. The water content of cocoa Fat

The moisture content is done by first considering the material weighing 2 grams and inserted into a cup that is already known is heavy does it weigh. Subsequently incorporated into the oven with a temperature of $105 \mathrm{C}$ to a constant weight. Then chill the ingredients for 20-30 minutes in the desiccator and calculate moisture content with the equation (2).

\section{RESULTS AND DISCUSSION}

\section{A. The process of making Tools}

Fat cocoa is produced by using the tool pressed with Hydraulic Unit type brand Carver 3912 Models equipped with pressure and temperature. In addition to putting pressure the cocoa from nib, the tool also delivers heat to the material so that it is capable of removing the fat cocoa from nib. In addition, in order for the utilization of this tool can work better then to obtain the optimum results for cocoa fat done making the unit a tool like in Figure 1 to support the performance of the tool.

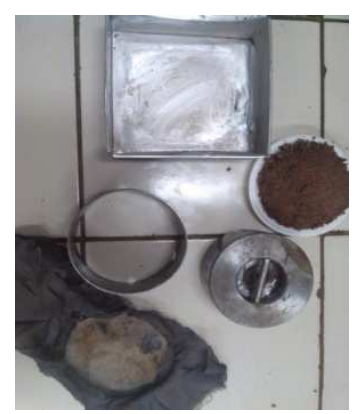

Fig. 1. Component of Tools Press

The working principle of the tool by using the hydraulic jack which will lift the bottom of the tool upwards until the cavity between the heater elements is closed, the pressure will give force to the cross-sectional area and the temperature is set at $130{ }^{\circ} \mathrm{C}, 150{ }^{\circ} \mathrm{C}$ and $170{ }^{\circ} \mathrm{C}$ for treatment in this study. The function of this tool is to separate the fat cocoa from nib. Ability to work effectively in different situations, and with various individuals or groups (flexibility) 
multycommodities as well as the advantages of cheap and easy care as well as easy operation and good results.

Technical specifications of tools, capacity continuous in this study is $160 \mathrm{~g}$ cocoa powder, hydraulic jack, heater (15 $\mathrm{cm} \times 15 \mathrm{~cm})$. iron construction materials $(11 \mathrm{~kg})$, iron pipes. This tool has the advantage, in addition pressing also have a heating element. So while cocoa will receive ongoing presses heat until all the fat cocoa is expected to be issued.

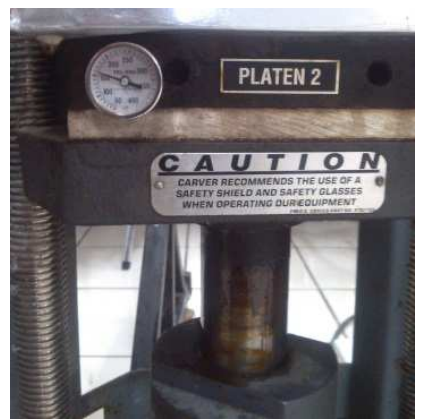

Fig. 2. Heating Elements

If the pressure and given time are so greater it will be the greater amount of cocoa fat tally that could be generated. In addition, the principle of work of these tools should be supported also by the units that exists on the device. Tool press has been fitted the units that supports. However, in this study adds new unit aims to optimize the performance of the tool. The Unit is part of the suppressor on the tools in the form of solid iron pejal enabled to press when pressing the materials.

This is a very important part in the process because the power pressesgiven material is optimal in split cells until the cocoa nib produced fat cocoa.

That is the function unit in the appliance. Starting from hydraulic jack that serves as a driving force in order to produce pressure and cylinder blocks (spaces press) that serves to position the material, iron pipe as an adhesive iron as not to run out of position during the process, and then presses the fabric filter used to wrap the cocoa powder is aimed at separating fat cocoa and cocoa for cake.

Testing of the prototype instrument farm machinery press cocoa powder on this study examines the extent to which the tool is working to solve the problem of mechanization and production process in getting fat cocoa, also can be expected to open up opportunities for increasing production capacity which in turn makes the product processed foods potentially Brown.

\section{B. The Testing of Press tool}

The testing tools is carried out using a temperature of $130{ }^{\circ} \mathrm{c}, 150{ }^{\circ} \mathrm{C}$ and $170{ }^{\circ} \mathrm{C}$ with pressure 8.05 MPa. To achieve these temperatures require different times that is 10 minutes to $130 \mathrm{C}, 12$ minutes the temperature of $150{ }^{\circ} \mathrm{c}$, and 15 minutes to $170{ }^{\circ} \mathrm{c}$. The temperature cooled the entire surface will be the field elements and pressed material. To observe the first presses in temperature until the desired temperature is approaching minimum $10 \mathrm{C}$, and after approaching the temperature hydraulic jack in gently until the block cylinder cover.
The tool testing results obtained during the period of the study is to obtain data about the ideal conditions to do presses where the variable pressure, temperature, and time. During the assessment tools there are some results that can be informed, among others, the pressure used is $8.05 \mathrm{MPa}$. With pressure so the operation of the tool will support the current process of presses, because the pressure is great to be able to break up the cells of cocoa nib being more devastated and removing fat from the presses results.

The pressure does not influence the tools and materials even unit though. This has been designed and is designed according to your needs. This tool also could have been operated in accordance with its use because each unit of a well-functioning and mutually support each other. In addition to the pressure, the temperature generated by the elements work well it views with the study conducted during the process of presses.

The heat are produced is able to make cocoa powder melts and flows into the container. Time presses about 12 minutes until the fat is no longer flowing marked decrease in pressure to $2,964 \mathrm{MPa}(15,000$ pounds). At time when the pressure of 5,000 Pounds of fat little by little started to come out of the material. This is done on each of the presses. Then, the products generated by this tool is in the form of cocoa fat. So the tool can already operate in accordance with the used both short term and long term for the preparations that need to be extracted through a process of presses.

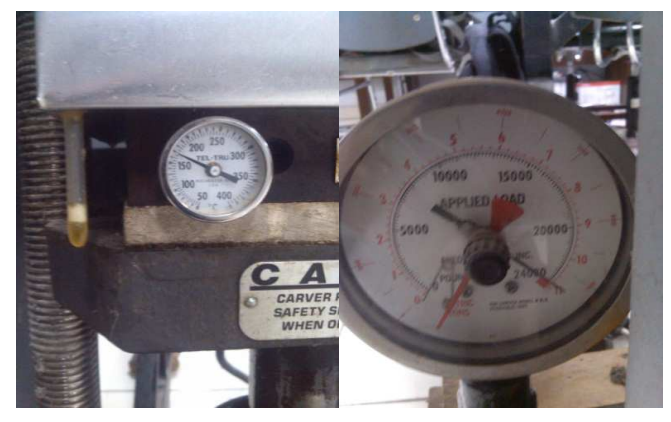

Fig. 3. Amperage Gauge Pressure and Temperature Ampere

The Use of the component capable of producing cocoa fat gain the optimal use of information tools coupled to specify variable presses. These variables i.e. pressure $\mathrm{MPa}, 8.05$, thetemperature $130 \mathrm{C}$ is the ideal conditions in the cocoa fat presses. Therefore, this tool can be useful and beneficial is projected to extract various commodities through the process presses.

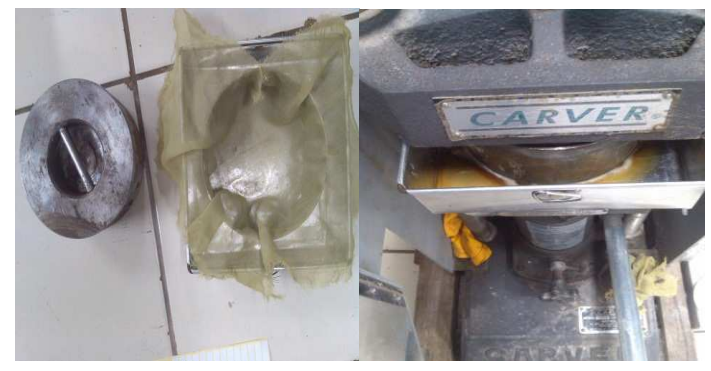

Fig. 4. Materials and Tools and tool Condition Unit Presses 


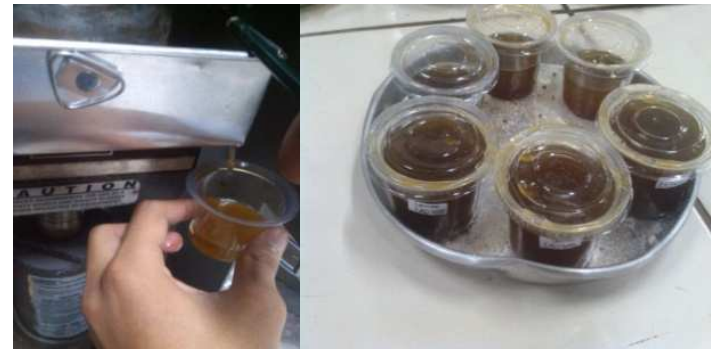

Fig. 5. Retrieval of Fats Results as Product and Presses

Based on Poiseuille's law approach and relationship Carman Kozeny, pressure presses is one of the decisive parameters in getting fat from the solid substrate. With the higher pressure,the higher the ability to break up cells of cocoa nib and pushes fat to get out of the matrix of the nib. With the process of warming up, fat and viscosity becomes liquid fat will be reduced so that more fat makes it easy to get out of the matrix cells of cocoa.

\section{Roasting}

Cocoa beans that have been roasted peanuts have a distinctive scent of chocolate flavored intent osphronemidae, bitter and sour are low. In addition, drying is done in order to inflate grain leather so easily separated during stripping, and make more crisp to facilitate nib destruction. The temperature used during drying is $350 \mathrm{C}$ with the old drying 15 minutes and gained $2.15 \%$ water content. According to Widyotomo et al., [2] the process of drying takes place between 15-25 minutes depending on the capacity of load of roasted until retrieved the final moisture content of $2.5-3 \%$.

\section{The Percentage of Heavy Leather and Cocoa Nib}

How to get heavy leather and cocoa nib is done manually, i.e. peeling the beans with skin separates between the skin and the nib is a top priority for further processing. There are three treatment i.e. $200 \mathrm{~g}, 400 \mathrm{~g}, 600 \mathrm{~g}$. next lot nib resulting from any such treatment is weighed using digital scales similarly heavy early beans.

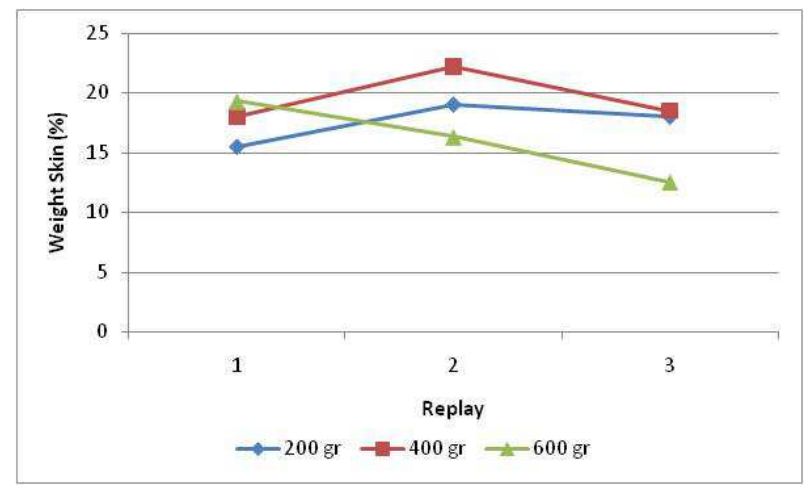

Fig. 6. The Percentage of Weight Of The Cocoa Skin

The cocoa beans are useful for further processing is the nib or meat beans, while the skin of the seed is a waste. Therefore, it is necessary to separate between the peeled skins with cocoa nib [3]. So, to determine the percentage of weight of the cocoa skin, whereas for the calculation of the weight of the nib is weighing the amount generated for each nib moderate. Process beans skin peeled and separated from nib then weighed using digital scales. Graph the percentage of weight of the cocoa skin can be seen in Figure 6.

In Figure 6, the graph having this caused heavy fluctuations of different materials, seeds are not uniform size of even the existence of the seeds involved skin nib. The process of separation of the skin is done because only the nib are used for further processing. Shell beans can cause destruction of the capacity of the mechanically very low seed [4].

On the image can be seen that heavy leather cocoa beans in each repeat of the same, there is no skin is wasted and there is the entrance of the weighted nib while stripping hard nib is separated from the chaff.This is due to several factors such as many beans are small so that when there are skin peeling nib sticking and weighted, human error, and conditions. The percentage of this skin is medium. In addition due to the size of the seed, less clean-washing after fermentation is also one of the causes of the high levels of the skin because there are still remnants of pulp that stick to the skin. According to Wahyudi et al., [5] a large cocoa beans have low levels of skin and vice versa, small sized beans have high levels of the skin. Data on the percentage of weight of the cocoa nib can be seen in Figure 7.

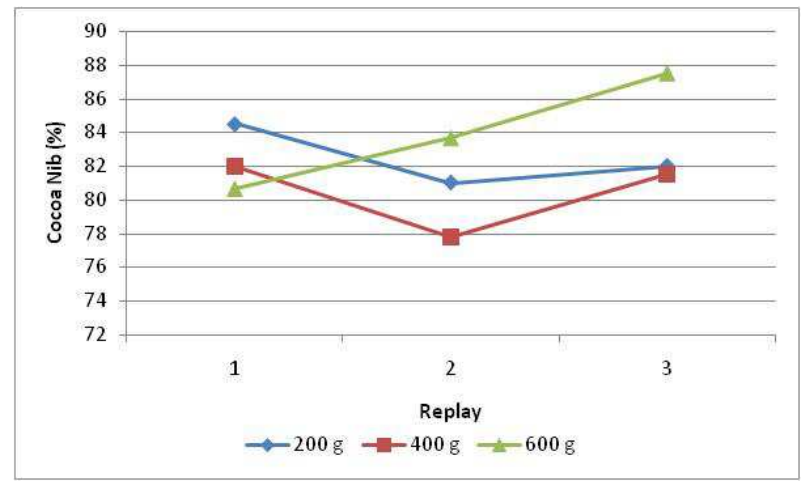

Fig. 7. The Percentage of Cocoa Nib

Figure 7 shows that stripping the skin dry or roasted cocoa beans aims to facilitate in cocoa in order to separate the skin peeling with nib and nib destruction to form a coarse powder so when cocoa powder presses will be easier removing the fat. The acquisition of nib on each repeat is not the same as a factor when the drying isnot produced the cocoa evenly so that when there is still a cocoa peeling a hard shelled and there is also some nib wasted due to presence of epidermis that is still attached to the nib. In addition, nib easily destroyed when stripping so there are some ingredients that are devastated and still weighed into the nib. This is seen in the skin of the percentage obtained.

$\mathrm{Nib}$ is the flesh of the fruit of the cocoa which becomes the raw material processing next. The resulting nib acquisition for each repeat of different thin and there are unisex which is down. The cause is likely a hard shelled cocoa beans due to a less drying time showers so it does not make the skin crispy cocoa. This will give the fat while gaining influence in the process presses. According to Wahyudi et al [5] manually seed skin splitting on cocoa beans water containing $6.5 \%$ obtained total $87,1 \%$ nib components. 


\section{E. The Cocoa Fat Yield}

Yield of fat obtained from cocoa presses process. Cocoa Nib blend until it becomes a powder. As many as $160 \mathrm{~g}$ ingredients cocoa powder rough weighed with each replay then wrap it into a fabric filter and put into a baking dish. The capacity of a continuous range of $160 \mathrm{~g}$ for every time presses. The temperature setting on the tool is done before the presses to take place, with a temperature of treatment $130{ }^{\circ} \mathrm{C}, 150{ }^{\circ} \mathrm{C}$, and $170{ }^{\circ} \mathrm{C}$. After approaching the temperature, the material has been placed to the tool exactly over the press heating element, wait until the temperature of the ingredients matched with constant temperature and then pressed with $8.05 \mathrm{MPa}$ pressure.

The weight yield of fat obtained from the number of cached fat in the container. The average weight Data yield cocoa fat after done presses can be seen in Table 1 .

Based on Table 1, visible that the largest percentage of fat obtained in sample quantities $200 \mathrm{~g}$ when compared to a sample of $400 \mathrm{~g} 600 \mathrm{~g}$. This may be due to sample a little more than the process optimized press because almost all the ingredients or cocoa can pressure so that more is coming out. The table above, it can be seen from the increase in the percentage of cacao fat yield after the presses with pressure, temperature and time. The largest percentage on the material pressure with a large $200 \mathrm{~g} 8.05 \mathrm{MPa}$ temperature $130{ }^{\circ} \mathrm{C}$ second repetition. While the ingredients $400 \mathrm{~g} 600 \mathrm{~g}$ cocoa fat gain value varies.

TABLE I

COCOA FAT YIELD (\%) WAS ONCE THE PRESSES

\begin{tabular}{|c|c|c|c|}
\hline \multirow{2}{*}{ Replay } & \multicolumn{3}{|c|}{ Cocoa Fat Yield (\%) } \\
\cline { 2 - 4 } & $\mathbf{2 0 0} \mathbf{g r}$ & $\mathbf{4 0 0} \mathbf{~ g r}$ & $\mathbf{6 0 0} \mathbf{~ g r}$ \\
\hline a & 46.79 & 34.22 & 41.66 \\
\hline b & 56.29 & 47.68 & 38.86 \\
\hline c & 51.65 & 49.67 & 38.79 \\
\hline Average & $\mathbf{5 1 . 5 8}$ & $\mathbf{4 3 . 8 6}$ & $\mathbf{3 9 . 7 7}$ \\
\hline
\end{tabular}

An increased amount of fat, resulting in fat weight just looks a bit of a difference. This is due to several factors including the size of the particles of the great cocoa powder so hard it split cells - cells of cocoa and is still suboptimal filter and a few more are still sticking to the baking pan, resulting in still presses results for cake is estimated to contain fat.Increase in the percentage of cacao fat yield after the presses in influence by pressure, temperature, and time presses. The pressure used by $8.05 \mathrm{MPa}$. An increase in the amount of fat produced because the big pressure, the emphasis and time units used the press tool. However, if the uses of temperature too high will trigger the point is a high free fatty acids.

The research is done trying to improve what has been scrutinized by investigators earlier in the press optimization tool, in order to simplify the process of data because the presses or the information has been delivered through this research. Thus it can be concluded that the more obvious functional unit tool then it will easy to give you information on technology presses of pressure, temperature, and the ideal time for cocoa powder presses for cocoa fat.

\section{F. The Heavy of Bungkil After The Process of Cocoa Presses}

The results obtained from cocoa powder presses there are two kinds of fat that cocoa and cocoa for cake. Fat cocoa is a top priority in efforts of such presses, while the cocoa for cake is a by-product of cocoa fat. Cocoa for cake obtained from results of the cocoa powder presses most fat has already been taken. However, this is later smoothened for cake to be processed in the form of powdered chocolate. The Data along with the acquisition of cocoa for cake after the heavy presses can be seen in the table below.

In Table 2, it can be seen that the percentage of cocoa for cake obtained when presses on each different replicates. It is influenced by the drying process, the amount for cake generated in accordance with the number of fat gained. Percentage for cake so it looks at the treatment of $200 \mathrm{~g}$ with a temperature of $130{ }^{\circ} \mathrm{C}$ pressure $\mathrm{MPa} 8.05$ in Deuteronomy to 2 has a small percentage of the amount of this is due to maximal support all the variables between the temperature, pressure, and time. In addition, treatment ingredients $400 \mathrm{~g}$ temperature $150{ }^{\circ} \mathrm{C}$ and $600 \mathrm{~g}, 170{ }^{\circ} \mathrm{C}$ for bungkil large acquisition this is due to less destruction of coarse powder cocoa until it is difficult to break down the cell powder-less than perfect, and moisture content of materials, then the amount of material that a lot of time presses take place.

TABLE II

The Percentage of Weight of Bungkil CocoA

\begin{tabular}{|c|c|c|c|c|c|c|}
\hline \multirow{2}{*}{ Replay } & \multicolumn{2}{|c|}{200 gr } & \multicolumn{2}{c|}{$\mathbf{4 0 0}$ gr } & \multicolumn{2}{c|}{$\mathbf{6 0 0}$ gr } \\
\cline { 2 - 7 } & $\begin{array}{c}\text { Weight } \\
\text { Powder } \\
\text { (gr) }\end{array}$ & $\begin{array}{c}\text { Weight } \\
\text { Bungkil } \\
(\mathrm{gr})\end{array}$ & $\begin{array}{c}\text { Weight } \\
\text { Powder } \\
(\mathrm{gr})\end{array}$ & $\begin{array}{c}\text { Weight } \\
\text { Bungkil } \\
\text { (gr) }\end{array}$ & $\begin{array}{c}\text { Weight } \\
\text { Powder } \\
(\mathrm{gr})\end{array}$ & $\begin{array}{c}\text { Weight } \\
\text { Bungkil } \\
(\mathrm{gr})\end{array}$ \\
\hline 1 & 156 & 53,20 & 298 & 65,77 & 468 & 58,33 \\
\hline 2 & 151 & 43,70 & 302 & 52,31 & 494 & 61,13 \\
\hline 3 & 151 & 48,34 & 310 & 50,32 & 464 & 61,2 \\
\hline Average & $\mathbf{1 5 2 , 7}$ & $\mathbf{4 8 , 4}$ & $\mathbf{3 0 3 , 3}$ & $\mathbf{5 6 , 1}$ & $\mathbf{4 7 5 , 3}$ & $\mathbf{6 0 , 2 2}$ \\
\hline
\end{tabular}

Then, still less the maximum filter as a result a lot of fat sticking strain and then the error in a filter fabric color selection impact on earnings results the cocoa fat. In addition less cables condition keep to electrical amperage that resulted in temperatures sometimes up and down because of the loss of electricity supply to the appliance.

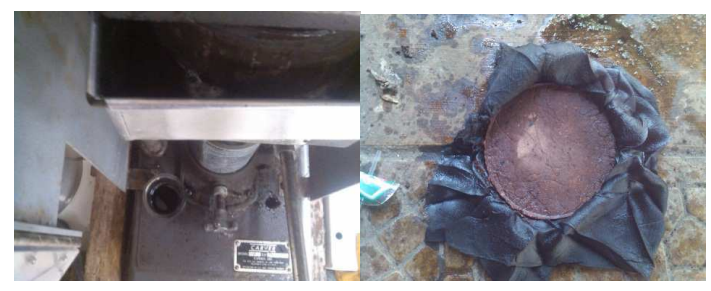

Fig. 8. Acquisition (A) Bungkil (b) The wrong filter

\section{G. Water Content of Bungkil Cocoa}

Moisture content is the amount of water left on bungkil. The moisture content of the material can facilitate microorganisms grow and damage the material. Moisture content is also one of the considerations in the sale of cocoa. Moisture content determine yield and also reflect the power save. Measurement of moisture content is performed on each treatment. The Data along with the acquisition of the average 
moisture content of bungkil cocoa after the presses can be seen in Table 3.

TABLE III

The Average Moisture Content (\%) OF BungKil CocoA After THE PRESSES

\begin{tabular}{|c|c|c|c|}
\hline \multirow{2}{*}{ Replay } & \multicolumn{3}{|c|}{ Average Moisture Content (\%) } \\
\cline { 2 - 4 } & $\mathbf{2 0 0} \mathbf{~ g r}$ & $\mathbf{4 0 0} \mathbf{g r}$ & $\mathbf{6 0 0} \mathbf{g r}$ \\
\hline a & 4,79 & 4,23 & 5,68 \\
\hline b & 5,62 & 4,75 & 5,14 \\
\hline c & 5,67 & 5,03 & 5,03 \\
\hline
\end{tabular}

In Table 3 it can be seen that the moisture content in price for each treatment and the lowest water levels in the treatment $150 \mathrm{C}$ the highest temperature $400 \mathrm{~g}$ on ingredients $600 \mathrm{~g} 170 \mathrm{C}$. However, there are several levels of water quality that qualify for cake cocoa SNI 7553: 2009, which requires moisture content maximum $5.0 \%$ cocoa powder. According to Beckett [4], during the drying will occur, among other changes in skin texture making it easy stripping seed skin and reduction of the water content.

The real effect of temperature of water content due to the heat that is transmitted until the powder melts and is able to make removing the fat. However, this water content on the data obtained were high in every treatment. It is influenced by the condition of the material at the time of drying the possibility of moisture content of materials is still high and the blend material is slightly rough-shaped still not smooth total so it is possible to condition the powder lasted not optimal presses, amount of material that a lot as well as a selection of filters which resulted in insufficient buildup on the filter cloth and the result of any insufficient presses. Moisture content of bungkil continued to decline along with the increase in temperature and a given time pres. The water that evaporates due to the warming being cooped up.

\section{H. The Cocoa Fat Samples Analysis}

\section{a. The Free Fatty Acids}

The levels of free fatty acids are fats that damage parameters due to the onset of the process hydrolase, triacylglycerol fatty acid produced from short-chain that creates a flavor and taste of rancid. The process of destruction by hydrolysis on the accelerated fat include moisture content, high temperatures and the presence of acid [3]. The analysis of fatty acid levels are based on a temperature treatment each time presses. Free fatty acids is expressed in per cent, calculated as free fatty acids oleic acid with $\mathrm{NaOH}$ normality 0,1025 and 28.2 constants which molecular weight oleic acid. The Data along with the acquisition of free fatty acid levels can be seen in Table 4.

TABLE IV

THE LEVELS Of FREE FATTY ACIDS ON FAT COCOA

\begin{tabular}{|c|c|c|}
\hline \multicolumn{3}{|c|}{ Level of Free Fatty Acid (\%) } \\
\hline Temp. $130{ }^{\circ} \mathrm{C}$ & Temp. $150{ }^{\circ} \mathrm{C}$ & Temp. $170{ }^{\circ} \mathrm{C}$ \\
\hline 2,61 & 3,15 & 4,42 \\
\hline
\end{tabular}

Based on the analysis, the real pressure had no effect on free fatty acids obtained. However, if the higher temperature then the free fatty acids are increasingly high. This is due to the free acid is not bound as the triglyceride produced by hydrolysis and oxidation by a factor of heat, water, acidity and catalysts (enzymes).

One of the causes of high free fatty acids is the use of high temperatures. The high temperature causes compounds found in fat break down and not mutually binding then the fat was hard to last a long time for the next process. Then when the test occurs before doing a fairly long storage after the samples are ready-pressed. It likewise be the cause of high free fatty acids. So while doing the dissolving difficult the correct samples obtained - true nitration perfectly. Of all the levels of free fatty acids obtained on pressure $8,05 \mathrm{MPa}$ and a temperature treatment of no-fat cocoa that meets the quality standard specified by the SNI 3748: 2009 which maximum levels of free fatty acids on fat cocoa is $1.75 \%$.

Wahyudi et al., [5] stating that cocoa beans contain fats with high levels of free fatty acids might be due to the use of seeds from the fruit of the cocoa that is stricken with the disease, the drying too long postfermentation, storage for too long in humid conditions or with water levels above $8 \%$, as well as a storage for too long from the seeds of cultivate.

On the other research, the levels of free fatty acids which have an effect on the given temperature. Where is the higher temperature treatments increased free fatty acid levels. The results of research conducted as well as what is produced in research this time where the high free fatty acids influenced use of high temperature while doing press cocoa powder.

Another factor is the high possibility of free fatty acids is an experienced Cocoa nib microbial decomposition during the process of stripping the skin of cocoa beans in the open air even the seeds too long storage is estimated to cause high levels of free fatty acids.

\section{b. The Number of Iod on Cocoa Fatty}

The Iod Number analysis done on the cocoa fat for each treatment temperature and pressure presses. The Iod number expressed as grams/iod absorbed per 100 g. standard sodium solution of normality with a thiosulfate $0,0998 \mathrm{~N}$ and the volume of a solution of thiosulfate on penitraanblanko 46,8 $\mathrm{ml}$, as well as a constant number of 12.96 Iod. The Iod number Data on fat cocoa can be seen in Table 5 on each treatment temperature.

TABLE V

THE IOD NUMBER ON COCOA FATTY

\begin{tabular}{|c|c|c|}
\hline \multicolumn{3}{|c|}{ Iod Number (gr/iod) } \\
\hline Temp. $130{ }^{\circ} \mathrm{C}$ & Temp. $150{ }^{\circ} \mathrm{C}$ & Temp. $170{ }^{\circ} \mathrm{C}$ \\
\hline 67,98 & 69,39 & 68,92 \\
\hline
\end{tabular}

Iod number reflects the degree is not saturated compounds in fatty cocoa is produced. The higher number means the higher Iod also degrees not saturated so one instead, if the number is low, the iod also small degrees of not saturated. These results do not meet the standard of quality defined by the SNI 3748: 2009,limit the number of iod on fat cocoa is $33-42 \mathrm{gI} / 100 \mathrm{~g}$. This may be due to the process that is performed manually roasted with temperature and stirring or less constant caused by the fermentation process has not been perfect. 
c. The Number of Saponification on Cocoa Fatty

Determination of the number of saponification can be used to find out the nature of fat, to determine the molecular weight of a fat roughly. The small number of large saponification depending on the length of his short carbon chain fatty acid or it can also be argued that the magnitude of the numbers saponification depending on the molecular mass of the FAT. From table 11 can be seen in temperature affect the tally the number of saponification. At a temperature of $130{ }^{\circ} \mathrm{C}$ saponification number decreased compared to other temperatures. In contrast to $150{ }^{\circ} \mathrm{C}$ temperature and $170{ }^{\circ} \mathrm{C}$ high saponification number obtained and the number saponification having treatment for any temperature fluctuations

TABLE VI

NUMBER OF SAPONIFICATION

\begin{tabular}{|c|c|c|}
\hline \multicolumn{3}{|c|}{ Number of Saponification (mgKOH/gr) } \\
\hline Temp. $130{ }^{\circ} \mathrm{C}$ & Temp. $150{ }^{\circ} \mathrm{C}$ & Temp. $170{ }^{\circ} \mathrm{C}$ \\
\hline 34,63 & 40,12 & 48,03 \\
\hline
\end{tabular}

According to SNI 3748: 2009 quality requirements as saponification number of fat cocoa is $188-198 \mathrm{mg} \mathrm{KOH} / \mathrm{g}$ of fat. From the results of the analysis of numbers saponification maximum obtained at 8.05 pressure MPa and temperature $1700 \mathrm{c}$ i.e. 48,03, but not a sufficient condition for quality from the number saponification. The magnitude of the number of saponification depends on the molecular weight. The number of saponification is usually associated with a molecular weight of oil/fat. If one has small molecular weight fatty so large and so saponification number instead. So also in the other treatments, the number of saponification obtained only range from $34-48 \mathrm{mg} \mathrm{KOH} / \mathrm{g}$ of fat. Therefore all iod number tally for each treatment does not meet standards.

\section{d. Water Content (b/b) in Fatty Cocoa}

Analysis of water content in the fat of cocoa performed at any temperature and pressure treatment time presses. Moisture content obtained from measurements of water content using the oven. Moisture content of cocoa fat expressed in percent, by reducing the weight of the initial material with heavy end of material after toasted. Data acquisition and its moisture content of cocoa fat can be seen in Table 7 levels of cocoa fat water.

Moisture content of cocoa fat obtained the research can be seen in table 7. Visible moisture content which is not uniform. Varicosity of moisture content is caused due to room temperature and humidity vary. In addition, the uptake of fat in each treatment were not in the same time.
TABLE VII

MOISTURE CONTENT OF COCOA FAT

\begin{tabular}{|c|c|c|}
\hline \multicolumn{3}{|c|}{ Moisture Content (\%) } \\
\hline Temp. $130{ }^{\circ} \mathrm{C}$ & Temp. $150{ }^{\circ} \mathrm{C}$ & Temp. $170{ }^{\circ} \mathrm{C}$ \\
\hline 0,34 & 1,02 & 1,99 \\
\hline
\end{tabular}

All the moisture content obtained at a temperature pressure MPa $8.05130{ }^{\circ} \mathrm{C}$ moisture content of this almost meets the quality standard moisture content level, but for other treatment brings moisture content ranged from $1.00 \%$ to $1.99 \%$, moisture content is far from standard quality level. In addition, according to SNI 3748: 2009 water levels on cocoa the maximum fats $0.2 \%$. Water levels of processing, in which a minimum is expected because of the quality of fat which can guarantee long lasting.

\section{CONCLUSIONS}

Based on the results of the research that has been done can be taken a few conclusions as follows : Press tool brand Hydraulic Unit type Model CARVER 3912 that has been supporting unit, made more practical presses and obtained good results. Information in the form of data namely pressure presses $8.05 \mathrm{MPa}$ with a temperature of $130{ }^{\circ} \mathrm{C}$ will yield a good fat, free fatty acids, then the number of iod, penyabunan that are not too high.

Based on the research that has been done the advice is as follows : In this study suggested that finding a good temperature and pressure in presses to produce the optimum cocoa fat. The use of press tools are rated much more practical, easy to operationalize as well as the cost is not too high as compared with the conventional way. For further research in order to take better care of the fabric filter (filter) and do not use temperatures above $130{ }^{\circ} \mathrm{C}$ for commodity cocoa presses.

\section{REFERENCES}

[1] Roeshandy, Y.M.S. 2013.Pengaruh Tekanan dan Suhu Terhadap Jumlah Lemak yang Dihasilkan dari Biji Kakao (Theobroma cacao L) dengan Alat Pengepresan.

[2] Widyotomo, S., Sri-Mulato dan E. Suharyanto.2006. Optimasi Mesin Sangrai Tipe Silinder Horizontal untuk Penyangraian Keping Biji Kakao. Pelita Perkebunan.

[3] Djadmiko, B.and A.P. Widjaja. 1985. Teknologi Lemak dan Minyak I. Agro Industri Press. Fateta-IPB. Page 92.

[4] Beckett, S.T, 2000. The Science of Chocolate, RSC Backs, Published by The Royal Society of Chemistry, Thomas Graham House, Science Park.Milton Road, Cambridge.

[5] Wahyudi T., Pujianto, dan T.R.Panggabean, 2008. Panduan Lengkap Kakao. Penebar Swadaya, Jakarta. 